\title{
Insulin Autoimmune Syndrome: a rare cause of postprandial hypoglycemia
}

\section{Pooja Sahni, Nitin Trivedi and Abdulkadir Omer}

Division on Endocrinology and Metabolic Medicine and Department of Internal Medicine, St Vincent Hospital, Worcester, Massachusetts, USA
Correspondence should be addressed to A Omer

Email

abdulkadir.omer@

stvincenthospital.com

\section{Summary}

A 65-year-old obese Caucasian woman presented with symptomatic postprandial hypoglycemic episodes, resolution of symptoms with carbohydrate intake and significantly elevated anti-insulin antibody levels. She did not have any evidence for the use of oral antidiabetic medications, insulin, herbal substances, performing strenuous exercise or history of bariatric surgery. Fingerstick blood glucose readings revealed blood sugar of $35 \mathrm{mg} / \mathrm{dL}$ and $48 \mathrm{mg} / \mathrm{dL}$, when she had these symptoms. Her medical history was significant for morbid obesity, hypothyroidism and gastro esophageal reflux disease. Her home medications included levothyroxine, propranolol and omeprazole. A blood sample obtained during the symptoms revealed the following: fingerstick blood sugar $38 \mathrm{mg} / \mathrm{dL}$, venous blood glucose $60 \mathrm{mg} / \mathrm{dL}$ (normal $(n$ ): $70-99 \mathrm{mg} / \mathrm{dL}$ ), serum insulin $202 \mathrm{IU} / \mathrm{mL}(n:<21)$, proinsulin $31.3 \mathrm{pmol} / \mathrm{L}(n:<28.9)$, C-peptide $8 \mathrm{ng} / \mathrm{mL}(n: 0.9-7)$, betahydroxybutyrate $0.12 \mathrm{mmol} / \mathrm{L}(n: 0.02-0.27)$ anti-insulin antibody $>45.4 \mathrm{U} / \mathrm{mL}(n:<0.4)$. The result obtained while screening for serum sulfonylurea and meglitinides was negative. The repeated episodes of postprandial hypoglycemia associated with significantly elevated anti-insulin antibodies led to a diagnosis of insulin antibody syndrome (IAS). Significant improvement of hypoglycemic symptoms and lower anti-insulin antibody levels $(33 \mathrm{U} / \mathrm{mL})$ was noted on nutritional management during the following 6 months. Based on a report of pantoprazole-related IAS cases, her omeprazole was switched to a $\mathrm{H} 2$ receptor blocker. She reported only two episodes of hypoglycemia, and anti-insulin antibody levels were significantly lower at $10 \mathrm{U} / \mathrm{mL}$ after the following 12 -month follow-up.

\section{Learning points:}

- Initial assessment of the Whipple criteria is critical to establish the clinical diagnosis of hypoglycemia accurately.

- Blood sugar monitoring with fingerstick blood glucose method can provide important information during hypoglycemia workup.

- Autoimmune hypoglycemia is a rare cause of hypoglycemia, which can be diagnosed on high index of clinical suspicion and systematic evaluation.

\section{Background}

Insulin autoimmune syndrome (IAS) - a rare cause of autoimmune hypoglycemia - was first described in a study by Hirata et al. in Japan in 1970 (1). It is characterized by spontaneous hypoglycemia, elevated insulin levels and elevated anti-insulin antibody levels. Typically, it is known to occur in patients exposed to insulin analogues (1). Other medications such as alpha lipoic acid (2) and sulfa-containing drugs such as procainamide, methimazole and hydralazine have also been found to be associated with IAS (3). We present a rare case of IAS in a patient with morbid obesity and prediabetes and using omeprazole.

\section{Case presentation}

A 65-year-old Caucasian woman was referred to the endocrinology clinic with a 6-month history of recurrent 
symptoms (once a week) of sweating, headache and confusion occurring $2 \mathrm{~h}$ after meals. She reported no symptoms during fasting state. The fingerstick blood sugar readings during these symptoms were $35 \mathrm{mg} / \mathrm{dL}$, $38 \mathrm{mg} / \mathrm{dL}$ and $48 \mathrm{mg} / \mathrm{dL}$, which were obtained using her husband's glucometer. She was familiar with the symptoms of hypoglycemia as her husband has type 2 diabetes. She reported improvement of symptoms after intake of sugar-containing drinks. She denied using insulin, oral hypoglycemic agents, herbal substances or exercising vigorously. She has not undergone any bariatric procedure. She denied excessive alcohol intake.

Her medical history was significant for morbid obesity with a BMI of $40 \mathrm{~kg} / \mathrm{m}^{2}$, hypothyroidism, hyperlipidemia, migraine and gastroesophageal reflux disease. Her home medications included levothyroxine, propranolol, omeprazole and pravastatin. Her physical examination was unremarkable except for morbid obesity. She did not have acanthosis or skin tags, and she did not have any evidence for poor peripheral blood circulation.

\section{Investigation}

She was recommended to monitor her blood sugar levels at home and to come to the laboratory when she experiences hypoglycemic symptoms. She was driven to the laboratory by her daughter during a hypoglycemic episode when the fingerstick blood sugar at home was $38 \mathrm{mg} / \mathrm{dL}$. Her venous blood sample during that episode (within the following $60 \mathrm{~min}$ ) showed blood glucose of $60 \mathrm{mg} / \mathrm{dL}$, together with an elevated serum insulin level of $202 \mathrm{IU} / \mathrm{mL}$, an elevated serum proinsulin level of
$31.3 \mathrm{pmol} / \mathrm{mL}$ and serum C-peptide level of $8 \mathrm{ng} / \mathrm{mL}$. The serum anti-insulin antibody level was over $45.4 \mathrm{U} / \mathrm{mL}$. The result obtained while screening for serum sulfonylurea and meglitinide was negative, and beta-hydroxybutyrate level was $0.12 \mathrm{mmol} / \mathrm{L}$. Based on the classical symptoms of hypoglycemia, concurrent low blood sugar levels and significantly elevated anti-insulin antibody levels, IAS was diagnosed. Further workup showed an Hb A1c level of $6 \%$. HLA II testing revealed the presence of DRB1*03, DRB1*14 and DRB ${ }^{*} 02$. The glutamic acid decarboxylase antibody was negative. We did not perform oral glucose tolerance test (OGTT) as we obtained the evidence of hypoglycemia and typical biochemistry suggestive of IAS.

\section{Treatment}

The treatment options were discussed, including nutritional management and corticosteroid use. The patient opted for nutritional management targeting portion size control and weight loss as recommended by American Diabetes Association.

\section{Outcome and follow-up}

At six-month follow-up, she reported a decrease in the frequency of hypoglycemia symptoms, occurring only once every month. She lost 6 pounds of weight, her HbA1c improved to $5.7 \%$ and anti-insulin antibody levels came down to $33 \mathrm{U} / \mathrm{mL}$. Based on a report of pantoprazole-related IAS cases (3), her omeprazole was switched to an $\mathrm{H} 2$ receptor blocker famotidine. Over the next 12 months, she reported only two episodes

Table 1 Laboratory results during initial and subsequent follow-up visits.

\begin{tabular}{l}
\hline Parameter \\
\hline BMI \\
Hemoglobin A1C \\
Fingerstick blood glucose \\
Venous blood glucose \\
Serum insulin \\
Serum proinsulin \\
Serum C-peptide \\
Serum sulfonylurea and meglitinides \\
Serum beta-hydroxybutyrate \\
Serum anti-insulin antibody
\end{tabular}

\begin{tabular}{c}
\hline $\mathbf{1 0 / 1 9 / 1 3}$ \\
\hline \\
\\
113 \\
217 \\
46 \\
7.6 \\
0.05 \\
\hline
\end{tabular}

\begin{tabular}{c}
\hline 12/5/2013* \\
\hline 40.2 \\
6 \\
38 \\
60 \\
202 \\
31 \\
8 \\
Negative \\
0.12 \\
$>45.4$
\end{tabular}

\begin{tabular}{c}
\hline $\mathbf{2 / 6 / 2 0 1 4}$ \\
\hline 40 \\
5.8 \\
75 \\
160 \\
4.3 \\
45 \\
\hline
\end{tabular}

\begin{tabular}{c|}
\hline $\mathbf{7 / 9 / 2 0 1 4 * *}$ \\
\hline 39.3 \\
5.7 \\
72 \\
88 \\
134 \\
22 \\
7 \\
\\
33 \\
\hline
\end{tabular}

\begin{tabular}{c}
\hline $\mathbf{1 / 1 5 / 2 0 1 5}$ \\
\hline 38.4 \\
5.7 \\
13 \\
\\
\\
\end{tabular}

\begin{tabular}{c}
\hline $\mathbf{7 / 3 1 / 2 0 1 5}$ \\
\hline 37.3 \\
5.7 \\
86 \\
84 \\
11.9 \\
5 \\
\\
10
\end{tabular}

\begin{tabular}{l} 
Reference range \\
\hline $20-25 \mathrm{~kg} / \mathrm{m}^{2}$ \\
$4.1-5.7 \%$ \\
$65-99 \mathrm{mg} / \mathrm{dL}$ \\
$65-99 \mathrm{mg} / \mathrm{dL}$ \\
$<201 \mathrm{U} / \mathrm{mL}$ \\
$<28.9 \mathrm{pmol} / \mathrm{mL}$ \\
$0.9-7 \mathrm{ng} / \mathrm{mL}$ \\
Negative \\
$0.02-0.27 \mathrm{mmol} / \mathrm{L}$ \\
$<0.4 \mathrm{U} / \mathrm{mL}$ \\
\hline
\end{tabular}

The diagnosis of insulin autoimmune hypoglycemia was confirmed with the presence of relevant symptoms, fingerstick blood sugar of $38 \mathrm{mg} / \mathrm{dL}$, venous blood glucose of $60 \mathrm{mg} / \mathrm{dL}$, significantly elevated insulin autoantibodies together with elevated serum insulin, proinsulin, C-peptide and negative sulfonylurea from the venous blood obtained during the symptoms (12/5/2013). Patient was placed on a nutritional management including meal portion control and avoidance of simple sugars. The patient was switched from omeprazole to famotidine on 7/9/2014. Serum insulin antibody, insulin and the proinsulin levels further decreased on repeat testing on 7/31/2015.

*Results obtained during an hypoglycemic episode. **Omeprazole was stopped. 
of hypoglycemia. The anti-insulin antibody levels were significantly lower at $10 \mathrm{U} / \mathrm{mL}, 12$ months after discontinuation of omeprazole (Table 1 ).

\section{Discussion}

This is a rare case of hypoglycemia of IAS in a morbidly obese female with prediabetes with A1C of $6 \%$. The diagnosis of hypoglycemia was based on the presence of Whipple's triad. Although a venous blood sugar of below $55 \mathrm{mg} / \mathrm{dL}$ is widely accepted as a cutoff limit for hypoglycemia in a non-diabetic subject, a blood glucose value of less than $60 \mathrm{mg} / \mathrm{dL}$ is also accepted as the definition of hypoglycemia if classic symptoms of hypoglycemia with relief of symptoms by raising the blood glucose is demonstrated (4).

When the patient was symptomatic, the fingerstick blood sugar was $38 \mathrm{mg} / \mathrm{dL}$ and the venous blood glucose was $60 \mathrm{mg} / \mathrm{dL}$ in the blood sample drawn within $60 \mathrm{~min}$ of the initial fingerstick reading without any intake of food or drink. Unfortunately, we do not have venous blood sugars at the exact time as fingerstick blood sugar was found to be $38 \mathrm{mg} / \mathrm{dL}$ because the patient had to be transported from home to the hospital laboratory. Furthermore, the blood sugar readings obtained with fingerstick method can be different than the blood sugar results of venous blood samples, and the blood sugar readings from a glucometer in the setting of hypoglycemia can be less accurate. However, it is a practical way of monitoring blood sugars and guides the clinician in decision making. A venous blood glucose of $60 \mathrm{mg} / \mathrm{dL}$ in a case with relevant symptoms, deserves further investigation for hypoglycemia in the clinical setting.

Insulin/C-peptide molar ratio was found to be $>1$ in most of the cases of IAS (5). There are at least 2 cases (one with type 2 diabetes and had A1C of 7\%) with IAS where insulin/C-peptide was $<1$ (6). The reason for this finding is not known. It is not clear if the diabetes status plays a role.

We did not consider analytical interference and we did not do heterophile antibody test. Actually clinical improvement of the symptoms alongside the decrease of the anti-insulin antibody profile during the course of the time may suggest that possibility of analytical interference was low. As there was no clinical evidence for type B insulin resistance, we did not check insulin receptor antibodies.

Medications with the presence of sulfhydryl groups are known to be associated with IAS (7). In a study that included 380 Japanese patients reported that approximately 50\% had prior exposure to drugs such as methimazole, penicillamine, glutathione, hydralazine, procainamide and isoniazid. There are case reports of IAS in patients using sulfhydryl-containing proton pump inhibitors including pantoprazole and omeprazole $(3,8)$. The mechanism of development of IAS with sulfhydryl group-containing drug is not entirely clear.

In our patient, the neuro-glycopenic symptoms occurred two hours after meals. This could be explained by dissociation of insulin from anti-insulin antibodies few hours after a meal. In the initial postmeal period, the insulin secreted in response to food intake was unable to act because it was bound to anti-insulin antibodies. Consequently, more insulin release occurs as high postprandial sugar continues to stimulate insulin production by the pancreatic $\beta$-cells. Approximately after two hours, hypoglycemia occurs due to the dissociation of insulin from anti-insulin antibody resulting in high levels of unbound insulin. Improvement of the hypoglycemic episodes with weight loss may be explained by the decrease in insulin peak after a meal due to decrease in insulin resistance. Moreover, low carbohydrate diet could also lead to lower postprandial insulin peak.

IAS is one of the disorders that has a strong association with the HLA haplotype. Most IAS cases have HLA DRB1*0406 suggestive of highest risk for susceptibility for Japanese IAS cases. The low prevalence of IAS among Caucasians can be explained by the low prevalence of DRB $1 * 0406$ in this population (9). One Bulgarian person with IAS reported to have DRB1*04:03, DRB1*15 (10) and a 7-year-old Brazilian women with IAS syndrome was reported to have HLA-DRB1*1104 genotype (11). There is no report showing HLA $\mathrm{B} 1{ }^{*} 03$ and $\mathrm{B} 3{ }^{*} 02$ and $\mathrm{DRB} 1{ }^{*} 14$ (as detected in our case) in Hirata syndrome. This finding suggests that the genetic spectrum of IAS seems to be more heterogeneous.

Different approaches for management of IAS have been described. In a previous study, most Japanese patients with IAS underwent spontaneous remission without any active intervention (7). Use of medications such as corticosteroids, cyclophosphamide, mycophenolate mofetil and chloroquine or plasma exchange has been found to improve hypoglycemia. In our patient, 6 months of implementing lifestyle modification lead to significant improvement in hypoglycemic symptoms and reduction in the levels of insulin antibody. It was not clear if discontinuation of omeprazole caused additional effect. 


\section{Declaration of interest}

The authors declare that there is no conflict of interest that could be perceived as prejudicing the impartiality of the research reported.

\section{Funding}

This work did not receive any specific grant from any funding agency in the public, commercial, or not-for-profit sector.

\section{Patient consent}

Written informed consent was obtained from the patient/mother for publication of this case report.

\section{Author contribution statement}

A Omer diagnosed and followed up the case, organized the data for publication, he and is responsible for accuracy and validity of the data. $P$ Sahni worked on data collection, obtained the consent from patient and helped in editing the draft of the manuscript. N Trivedi worked on editing and critical revision of the article.

\section{References}

1 Hirata Y, Ishizu H, Ouchi N, Motomura S, Abe M, Hara Y, Wakasugi H, Takahashi I, Sakano H, Tanaka M, et al. 1970 Insulin autoimmunity in a case of spontaneous hypoglycemia. Journal of the Japan Diabetes Society 13 312-320.

2 Chang HJ, Choi HS, Park MY, Leem SM, Jang YS, Park KS \& Lee JM 2009 A case of insulin autoimmune syndrome related to alpha-lipoic acid. Korean Journal of Medicine 76 600-604.
3 Gopal K, Priya G, Gupta N, Praveen EP \& Khadgawat R 2013 A case of autoimmune hypoglycemia outside Japan: rare, but in the era of expanding drug-list, important to suspect. Indian Journal of Endocrinology and Metabolism 17 1117-1119. (doi:10.4103/2230$8210.122644)$

4 Cryer PE, Axelrod L, Grossman AB, Heller SR, Montori VM, Seaquist ER, Service FJ\& Endocrine Society 2009 Evaluation and management of adult hypoglycemic disorders: an endocrine society clinical practice guideline. Journal of Clinical Endocrinology and Metabolism 94 709-728. (doi:10.1210/jc.2008-1410)

5 Wong S, Priestman A\& Holman AD 2014 Recurrent hypoglycemia from insulin autoimmune syndrome. Journal of General Internal Medicine 29 250-254. (doi:10.1007/s11606-013-2588-9)

6 Lupsa B, Chong A, Cochran EK, Soos MA, Semple RK \& Gorden P 2009 Autoimmune forms of hypoglycemia. Medicine 88 141-153. (doi:10.1097/MD.0b013e3181a5b42e)

7 Uchigata Y \& Hirata Y 2011 Insulin autoimmune syndrome (IAS, Hirata disease). In Immunoendocrinology: Scientific and Clinical Aspects, 1st edition, pp 343-367. Ed GS Eisenbarth. Totowa, NJ, USA: Humana Press.

8 Goodman LS, Gilman A, Hardman JG, Gilman AG \& Limbird LE 1996 Goodman and Gilman's the Pharmacological Basis of Therapeutics, 9th ed., p. 907. New York: McGraw-Hill.

9 Uchigata Y, Hirata Y, Omori Y, Iwamoto Y \& Tokunga K 2000 World-wide differences in the incidence of insulin autoimmune syndrome (Hirata disease) with respect to the evolution of HLA-DR4 alleles. Human Immunology 61 154-157. (doi:10.1016/S01988859(99)00144-5)

10 Sudano M, Turchi F \& Sossai P 2012 Insulin Autoimmune Syndrome (Hirata disease): case report in a Caucasian patient with new-onset diabetes. Clinical Medicine and Diagnostics 2 51-53. (doi:10.5923/j. cmd.20120205.02)

11 Alves C, Constança J, De León DD, Snider K \& Stanley C 2013 A novel atypical presentation of insulin autoimmune syndrome (Hirata's disease) in a child. Journal of Pediatric Endocrinology and Metabolism 26 1163-1166.

Received in final form 7 September 2016

Accepted 15 September 2016 